\title{
Impactos causados por vibrações mecânicas em chapas de alumínio no processo de laminação a frio
}

\section{Impacts caused by mechanical vibrations on aluminum sheets in the cold lamination process}

\author{
Alyson C. L. Silva ${ }^{1}$, Antonio R. Faria Neto ${ }^{1}$, Everton C. Medeiros ${ }^{1}$, Sofia Glyniadakis ${ }^{1}$, \\ Marcelo S. Martins*1
}

\begin{abstract}
RESUMO
O objetivo deste trabalho é analisar um dos principais problemas enfrentados pela indústria de laminação a frio na atualidade, a vibração mecânica. Fatores como tiras com alta velocidade para aumentar a produtividade e espessura cada vez mais finas fazem com que as vibrações estejam presentes o tempo todo durante a laminação. O objetivo inicial é analisar as forças que causam vibração em um laminador tipo quatro alto com dois estandes, onde é desejável identificar as origens dessas forças vibracionais para possibilitar dispensá-las ou pelo menos controlar sua intensidade, a fim de evitar danos na laminação e garantir a qualidade do produto ao cliente. Com estes dados poderá analisar as características das vibrações e atuar na sua eliminação. Ao final do trabalho espera-se demonstrar a importância da visão crítica do engenheiro na análise dos gráficos aliada aos cálculos da frequência natural de vibração e engajamento das peças-chave do laminador. Com essas duas ferramentas em mãos, será possível aumentar a produtividade do laminador e atuar preventivamente na manutenção, reduzindo assim seu tempo de parada e aumentando seu desempenho e eficiência.
\end{abstract}

Palavras-chave: Laminação de alumínio; Processo de laminação; Vibrações mecânicas.

\begin{abstract}
This paper purpose is to analyze one of the main problems faced by cold rolling industry of the current time, the mechanical vibration. Factors such as strips with high velocity in order to increase the productivity and thickness becoming thinner and thinner cause the vibrations to be present at all times during rolling. The initial purpose is to analyze the forces that cause vibration in a rolling mill type four high with two stands, where is desirable to identify the origins of these vibrational forces to make possible dismiss them or at least control its intensity, in order to prevent damage in the rolling mill and ensure product quality to the customer. With this data will be able to analyze the characteristics of the vibrations and act at your elimination. At the end of the work is expected to demonstrate how important the critical view of the engineer in the analysis of graphics combined with the calculations of the natural vibration frequency and engagement of key parts of the laminator. With these two tools at hand, will be possible to increase the productivity of the rolling mill and act preventively in maintenance, thereby reducing your downtime and increasing its performance and efficiency.
\end{abstract}

Keywords: Aluminum rolling; Rolling process; Mechanical Vibration.

${ }^{1}$ Universidade Estadual Paulista - UNESP - Campus de Guaratinguetá

*sampaio.martins@unesp.br 


\section{INTRODUÇÃO}

A cada dia os produtos são laminados a velocidades mais altas e a qualidade do produto final deve ser mantida e/ou melhorada. Por isso, é possível encontrar no mercado laminadores mais potentes e precisos, com tecnologia de ponta instalada. Porém, mesmo com todo esse investimento realizado, nem sempre é possível obter o que se deseja de imediato, muitas vezes a velocidade de laminação é limitada devido a problemas que ocorrem na chapa laminada, escorregamentos e muitas outras variáveis. Por isso é essencial que entendamos um dos agentes causadores dessas limitações, a vibração.

As vibrações mecânicas que ocorrem no processo de laminação são resultado das interações entre a estrutura do laminador e o processo de laminação. Quando ocorrem, as vibrações podem chegar a ocasionar variações na espessura e na qualidade superficial do produto laminado (HU; EHMANN, 2001). As forças dinâmicas observadas no processo acabam se refletindo na estrutura metálica do laminador, podendo causar variações no processo, como por exemplo o distanciamento dos rolos e/ou variação na velocidade de rotação dos mesmos (HU; EHMANN, 2001). Essas perturbações acabam causando variações na carga de laminação aplicada no processo, proporcionando novas vibrações e assim por diante. O estudo e os impactos causados por essas vibrações no processo de laminação, as quais são conhecidas como chatter, são de suma importância para a indústria de laminação.

De acordo com Roberts (1978), o processo de laminação envolve forças vibracionais que são auto excitáveis. Ele as dividiu em três grupos, que são amplamente conhecidos no meio acadêmico e industrial. Esses modos de vibração estão classificados conforme exemplificado abaixo:

- Chatter torcional (Torsional chatter), esse tipo de vibração ocorre principalmente entre as frequências de 5 até $20 \mathrm{~Hz}$;

- Terceira oitava (Third Octave) esse tipo de vibração ocorre principalmente entre as frequências de 125 até $240 \mathrm{~Hz}$;

- Quinta oitava (Fifth octave) esse tipo de vibração ocorre principalmente entre as frequências de 500 até $700 \mathrm{~Hz}$.

Na Figura 1 são apresentadas as forças impostas sobre os cilindros de laminação, conforme estudos conduzidos por Meehan (1998). 
Figura 1 - Modos de vibração

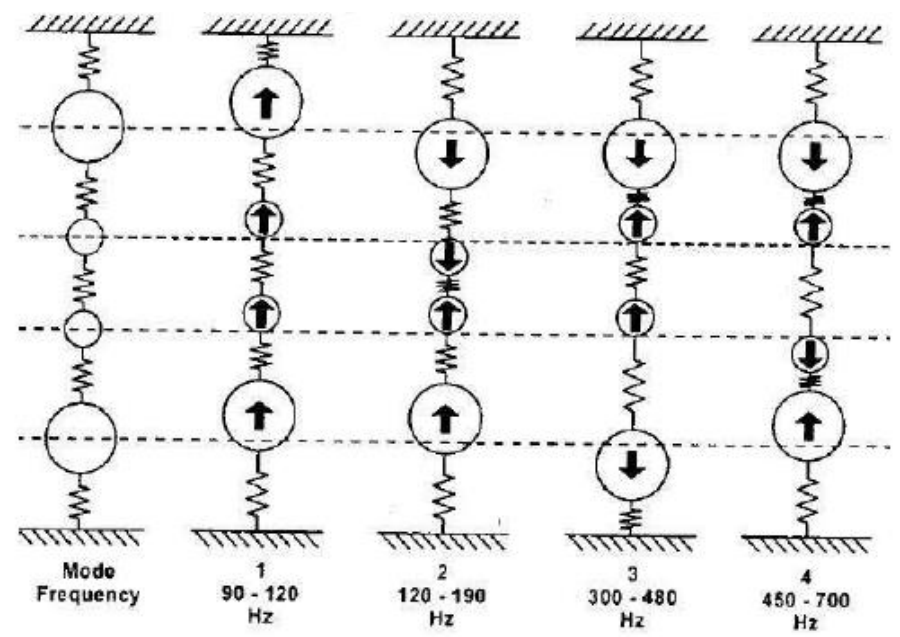

Fonte: Meechan (1998).

De acordo com Yun et al. (1995) o chatter torsional é responsável por causar padrões de variação na espessura da chapa laminada e também alterações na refletividade de sua superfície. Esse tipo de chatter é observado sob baixas frequências e é geralmente causado pelo sistema de acionamento ou controle do motor.

De acordo com Yun (1995) a terceira oitava ocorre entre as frequências de 120 a 300Hz. Inicialmente, esse fenômeno vibracional causa pequenas variações na espessura da tira, o que acaba criando uma componente dinâmica de força de laminação. Essa componente, flexiona a estrutura do laminador forçando uma variação entre a distância dos cilindros. Como resultado dessas interações, ocorre a variação das forças de laminação. Quando o estado de ressonância entre a estrutura do laminador e o processo de laminação é atingido gera-se instabilidade no processo. Em seu estudo, Tamiya (1980) classifica o fenômeno de terceira oitava como auto excitável em função do processo. Também é válido ressaltar que essa condição causa oscilações de maneira defasada nos cilindros de trabalho, degradando a superfície da tira, podendo até mesmo levar a sua ruptura dentro do laminador (YARITA et al., 1978). De acordo com Yun (1995) a ruptura da chapa dentro do laminador devido as oscilações causadas pelo chatter de terceira oitava podem também danificar o equipamento. As rupturas geralmente ocorrem em situações onde se buscam alta velocidade e/ou grandes reduções, características essas que estão diretamente relacionadas a produtividade do laminador. Roberts (1978) conclui que a otimização dos parâmetros operacionais, por exemplo o controle da carga de laminação, 
o controle do atrito entre chapa e rolo e das reduções da tira, podem minimizar a ocorrência do chatter de terceira oitava.

Vibrações de quinta oitava são geralmente caracterizadas por causar marcas nas chapas laminadas, perpendicular a direção de laminação. Essas marcas podem também ser impressas nos rolos de laminação e consequentemente causar a vibração de terceira oitava.

O propósito deste trabalho é estudar um laminador a frio do tipo quádruo, o qual mesmo com tecnologia suficiente para laminar a velocidade de 1800 metros por minuto atualmente opera com velocidade pouco superior a metade do que foi projetado. Essa limitação se dá devido as restrições causadas por vibrações mecânicas do próprio processo de laminação. Inicialmente será identificada a origem das fontes causadoras de vibrações mecânica para então atuar de forma a atenua-las.

\section{METODOLOGIA E DESENVOLVIMENTO}

Conforme apresentado pela Figura 1, há partes do laminador que são mais propícias a vibrações mecânicas que podem ser transmitidas para a chapa levando a formação do chatter. O intuito das discussões que virão a seguir irá objetivar na validação dessas informações, se essas regiões realmente podem impactar ou não na transmissão de vibrações, será estudado como lidar com essas situações adversas e analisar quais foram os impactos trazidos pela identificação do problema e da forma que se decidiu atuar, para orientar futuras intervenções em equipamentos que apresentam as mesmas características. Será também analisada algumas das frequências naturais do laminador, através de estudos conduzidos em parceria com a SKF, para que se possa evitar que o laminador opere na mesma frequência de operação e sua frequência natural.

Dentre os parâmetros avaliados destacam-se:

- Levantamento do diâmetro externo dos pescoços dos work rolls;

- Levantamento do diâmetro interno dos spindle pod;

- $\quad$ Inspeção das engrenagens da caixa redutora da cadeira 1;

- $\quad$ Inspeção das engrenagens da caixa redutora da cadeira 2.

Para obtenção dos dados que registram as vibrações mecânica, acelerômetros foram instalados na parte superior do laminador, de forma a registrar as vibrações que de fato se transferem para a estrutura física do laminador. Quando vibra, o laminador desloca 
a ponta do acelerômetro e sinais elétricos são enviados e armazenados no CPU. Para efetuar a leitura e interpretação dos dados foi utilizado o software IBA Analyser.

Na Figura 2 segue os registros obtidos no laminador nos primeiros meses de pesquisa.

Figura 2 - Espectro de vibração inicial

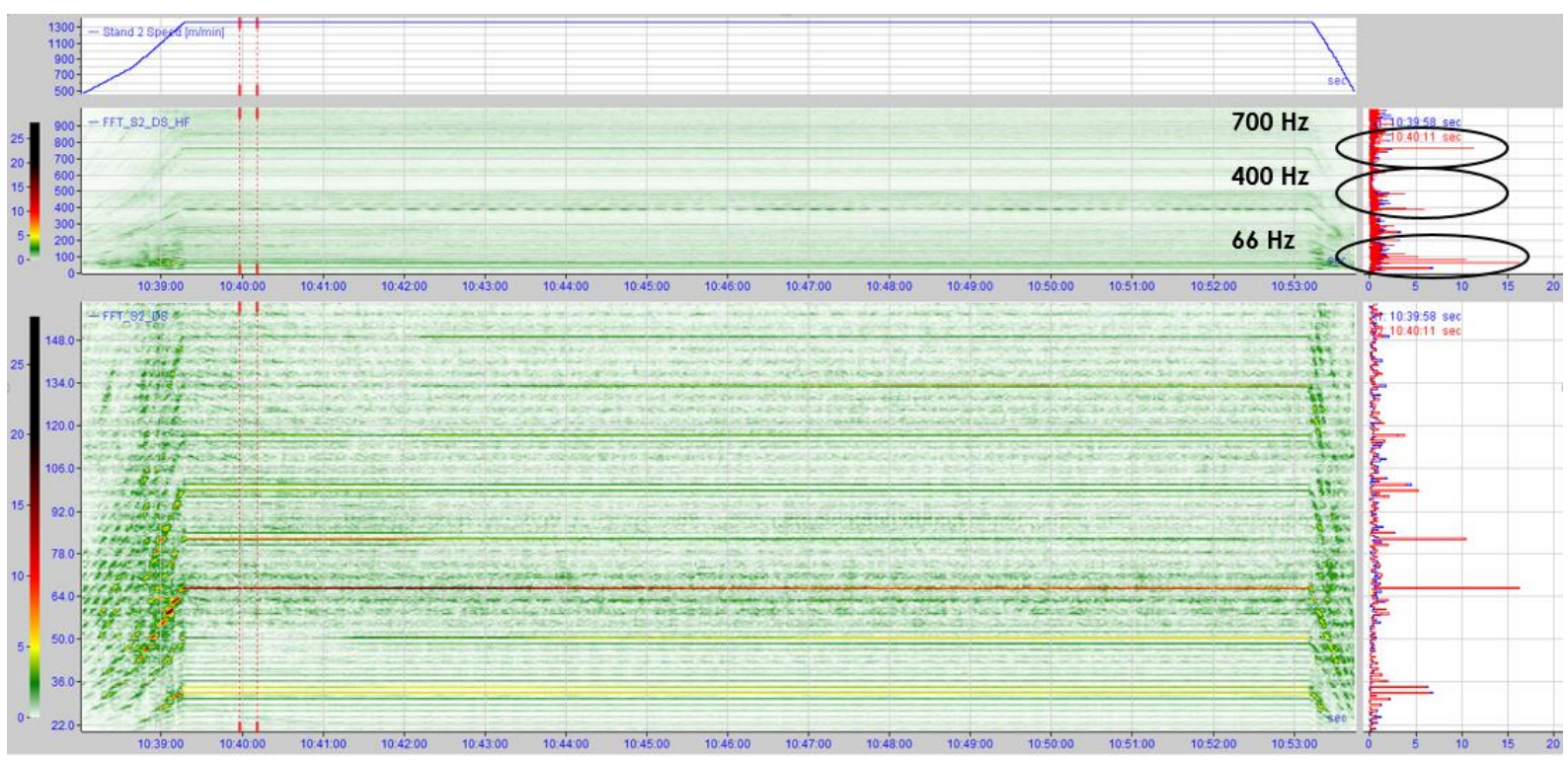

$\mathrm{Na}$ Figura 3, observa-se a faixa de frequência de 0 até $150 \mathrm{~Hz}$ onde são identificados vários picos de energia, cuja a intensidade chega a ultrapassar $10 \mathrm{mg}$.

Figura 3 - Espectro de vibração 2

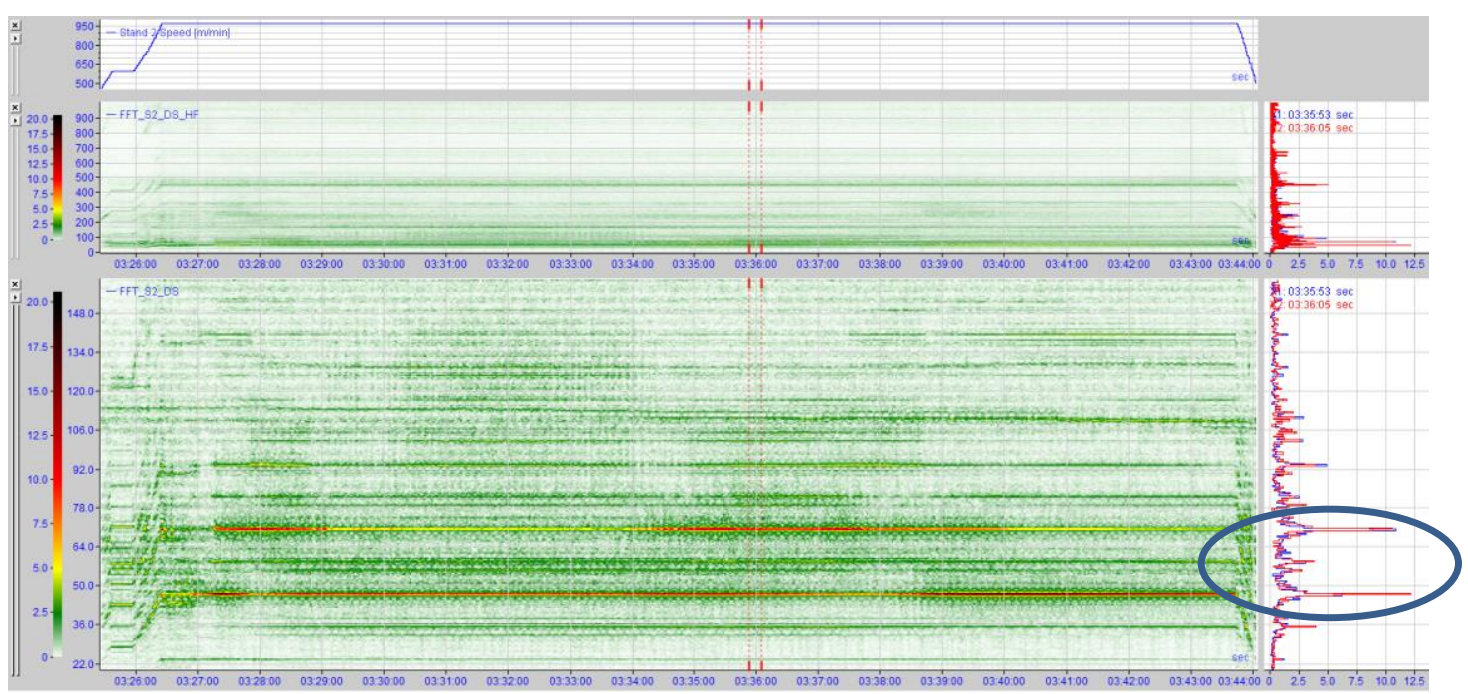

A Figura 4 representa uma situação crítica, esquerda, em contraposição com uma situação boa, direita. 
Figura 4 - Espectro de vibração bom x ruim

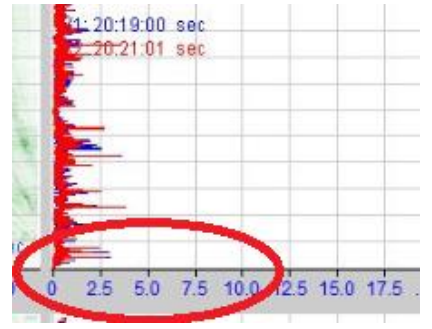

Bom

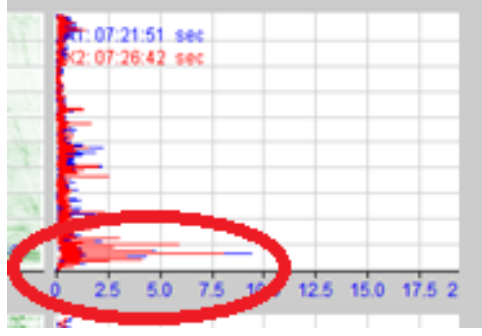

Ruim

Esse mesmo perfil de vibração foi observado em várias bobinas, sendo que para este caso específico a chapa laminada estava na velocidade de 950 [m/min], em outros casos também analisados a amplitude de vibração chegava a atingir níveis ainda mais altos, como 40 [mg], Figura 5.

Figura 5 - Espectro de vibração 3

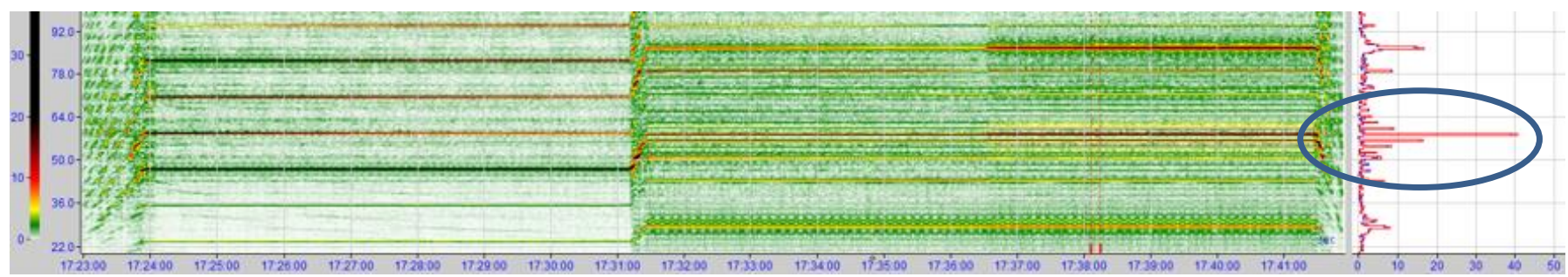

Iniciando a análise pela região de 0 até $150 \mathrm{~Hz}$, onde o problema é mais crítico, identifica-se que o espaçamento entre as bandas laterais de vibração ocorrem a cada 16 Hz, Figura 6. Direcionando para problemas na região do work roll.

Figura 6 - Espectro de vibração 4

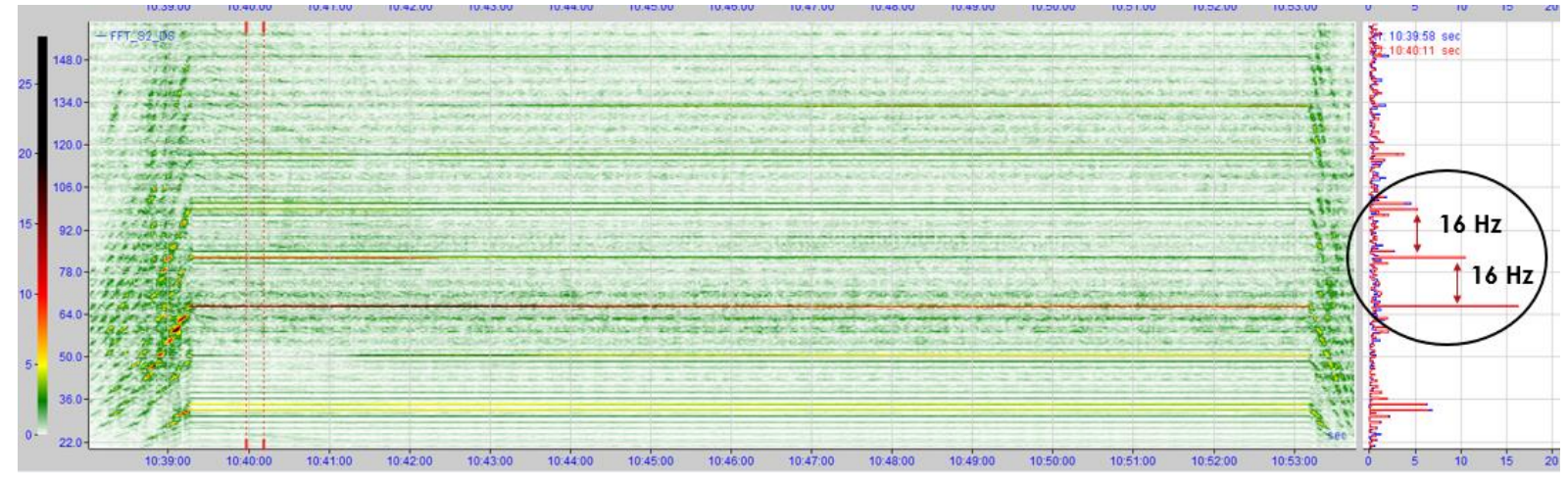

Essa análise também vai ao encontro com a teoria apresentada na Figura 1 onde foi afirmado que a dimensão inadequada do pescoço do cilindro de trabalho pode causar 
incitações que fazem o laminador vibrar, validando a hipótese de que algo realmente pode estar errado no cilindro de trabalho.

Em etapa inicial foi efetuada a medição do pescoço (Figura 7) de todos os cilindros de laminação utilizados no laminador.

Figura 7 - Pescoço do work roll

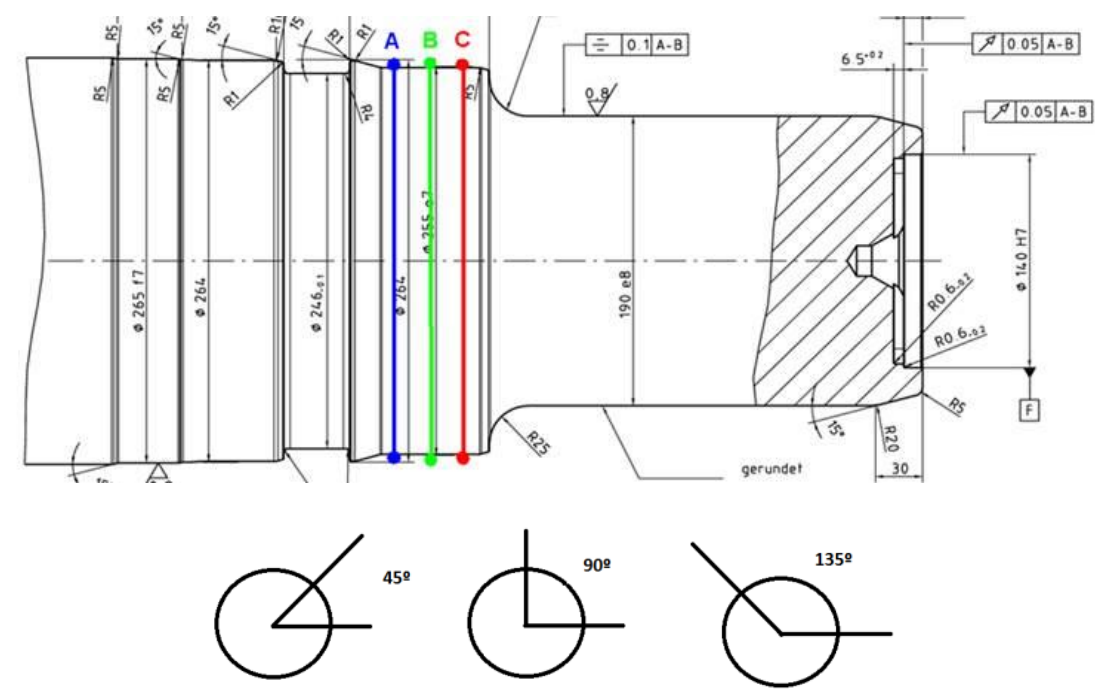

De acordo com o desenho do cilindro de trabalho, a medida do pescoço que entra em contato com o spindle pod deve possuir a dimensão de $255 \mathrm{e} 7$, o que de acordo com a NBR 6158 Sistemas de tolerâncias e ajustes dará as cotas de 254,890 e 254,828, para limites superior e inferior respectivamente.

Inspeções visuais nos cilindros também confirmam que eles estão em boas condições superficiais, Figura 8.

Figura 8 - Pescoço do cilindro de trabalho 


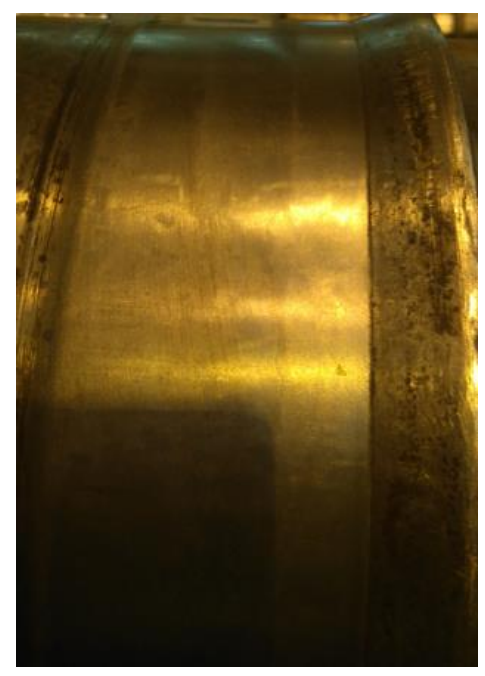

Concluindo que o desgaste não estava partindo dos cilindros de trabalho, partiu-se para a análise da peça na qual o cilindro se encaixa dentro do laminador, o spindle pod. Com a utilização de um micrômetro tubular.

A Figura 9 representa as dimensões da região do spindle pod que entra em contato com o cilindro de laminação. O diâmetro da região de contato é 255,03H7 o que segundo a NBR 6158 dará as tolerâncias 255,082 e 255,030, para os limites superior e inferior respectivamente.

Figura 9 - Spindle pod
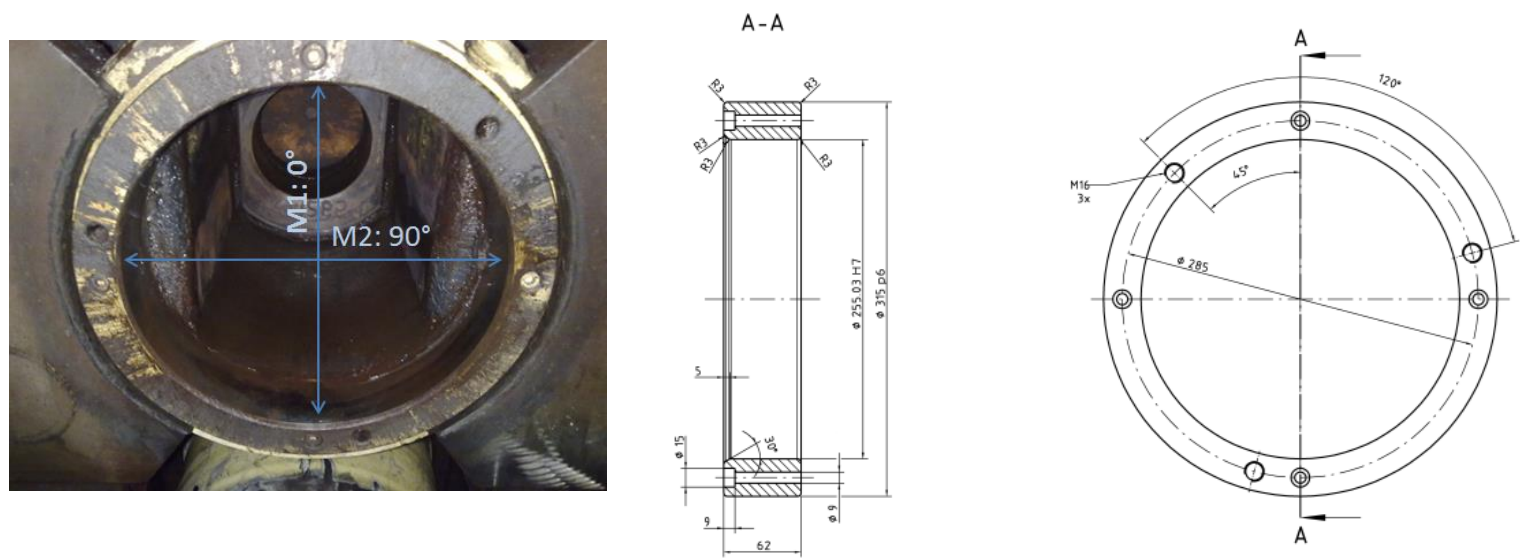

Com a utilização de um micrômetro tubular, foi executada a medição da região interna do spindle pod, nas posições M1 e M2, conforme representado na Figura 9. Os valores obtidos estão representados na Tabela 1.

Tabela 1 - Medida do spindle pod

\begin{tabular}{|l|l|l|}
\hline & $\mathrm{M} 1: 0^{\circ}$ & $\mathrm{M} 2: 90^{\circ}$ \\
\hline
\end{tabular}




\begin{tabular}{|l|l|l|}
\hline SUPERIOR & 255,500 & 255,040 \\
\hline INFERIOR & 255,460 & 254,960 \\
\hline
\end{tabular}

Pode ser observado o desgaste do spindle na posição M1, vertical, com isso a cada rotação do cilindro de trabalho uma força vertical é gerada, causando uma componente de força que é transmitida para o laminador.

A medida tomada para atuar nesse problema foi a troca da peça da região de contato entre o pescoço do cilindro de trabalho e o spindle pod.

\section{Caixa Redutora Cadeira 2}

Através de um estudo conjunto desenvolvido junto a SKF foi determinado a frequência natural de vibração da caixa redutora. O modelo discretizado em 65688 elementos sólidos e 180004 nós, conforme mostrado na Figura 10.

Figura 10 - Discretização da caixa redutora

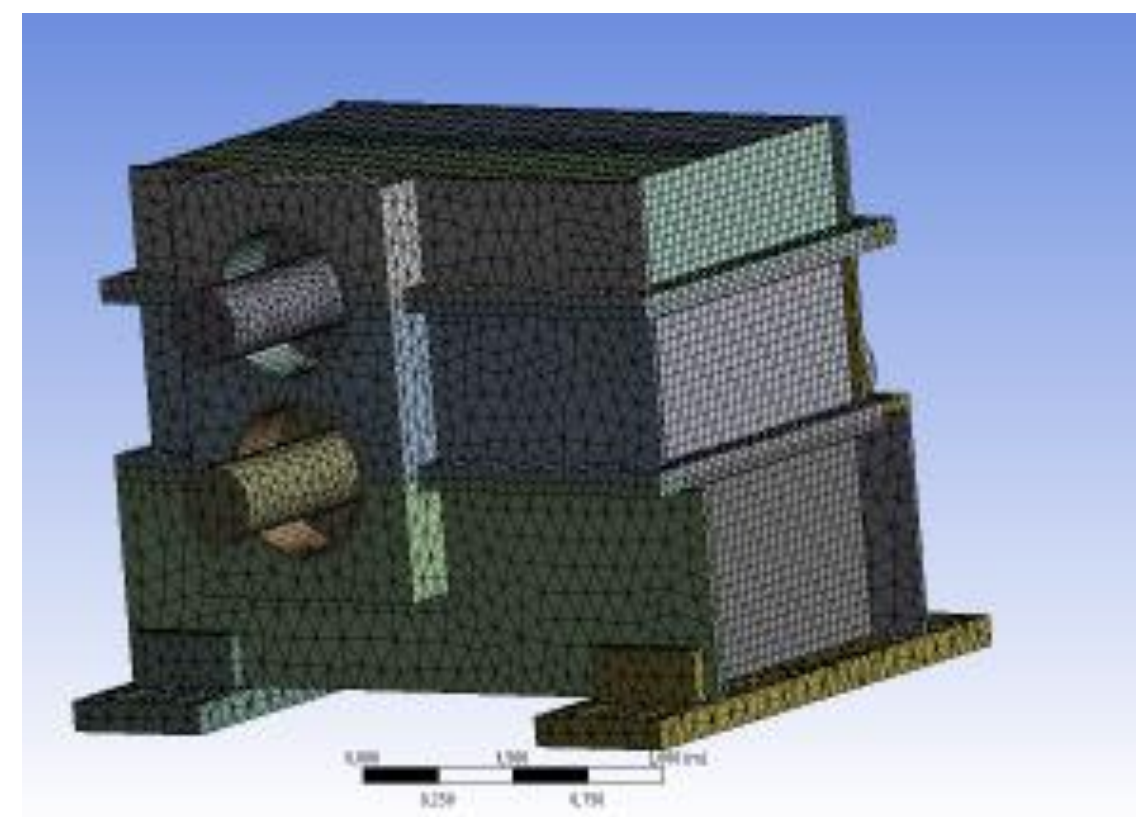

Foi efetuada a análise modal do conjunto, e de acordo com os dados obtidos, observou-se que a partir do $48^{\circ}$ até o $61^{\circ}$ modo de vibração, apresentam frequência natural na região entre 700 e $800 \mathrm{~Hz}$. Quando o sistema opera nessa frequência, geralmente entre as velocidades de 1200 até 1400 metros por minuto. O equipamento pode ser excitado e criar assim uma situação de ressonância no laminador. 
O software também indica a vibração na frequência de $700 \mathrm{~Hz}$ na velocidade de 1250 m/min, conforme pode ser observado na Figura 10 e na Figura 11, Observa-se que a amplitude dessa região é mais elevada do que em regiões vizinhas, indicando que o sistema está vibrando naquela frequência.

Como essa gama de velocidade é muito utilizada para que seja atingida a produtividade requerida, torna-se necessário analisar os impactos que atuar nessa velocidade podem causar ao processo.

Figura 10 - Espectro de vibração 5

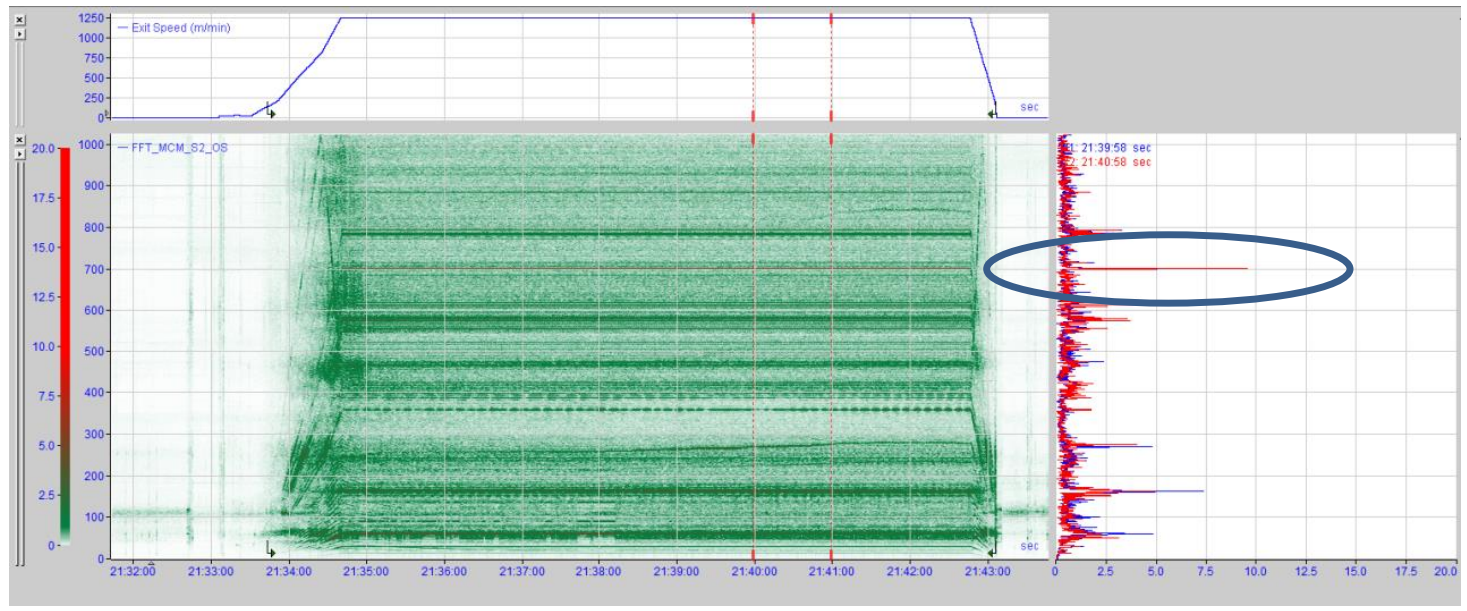

Figura 11 - Espectro de vibração região de 700 Hz

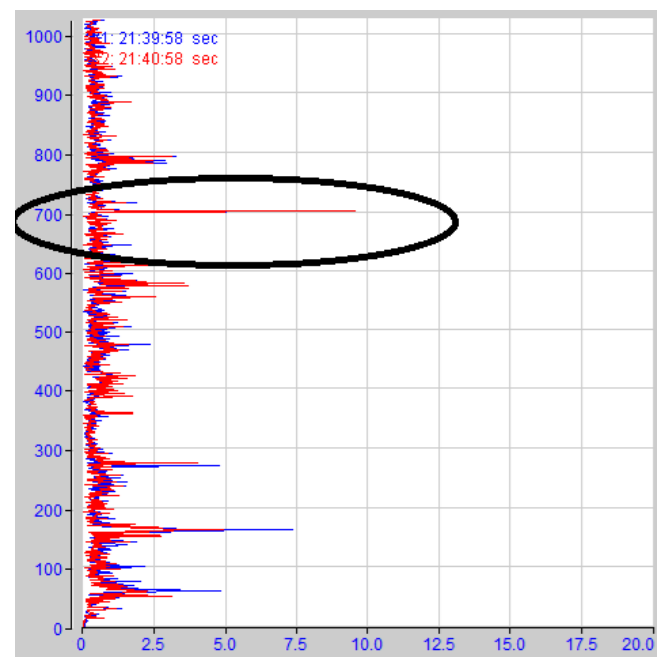

Abrindo a caixa redutora para inspecionar as engrenagens, observou-se que elas estavam apresentando desgaste no primeiro engrenamento. Conforme pode ser evidenciado em: Figura 12; Figura 13; Figura 14.

Figura 12 - Engrenagens da caixa redutora da cadeira 2 - Imagem 1 


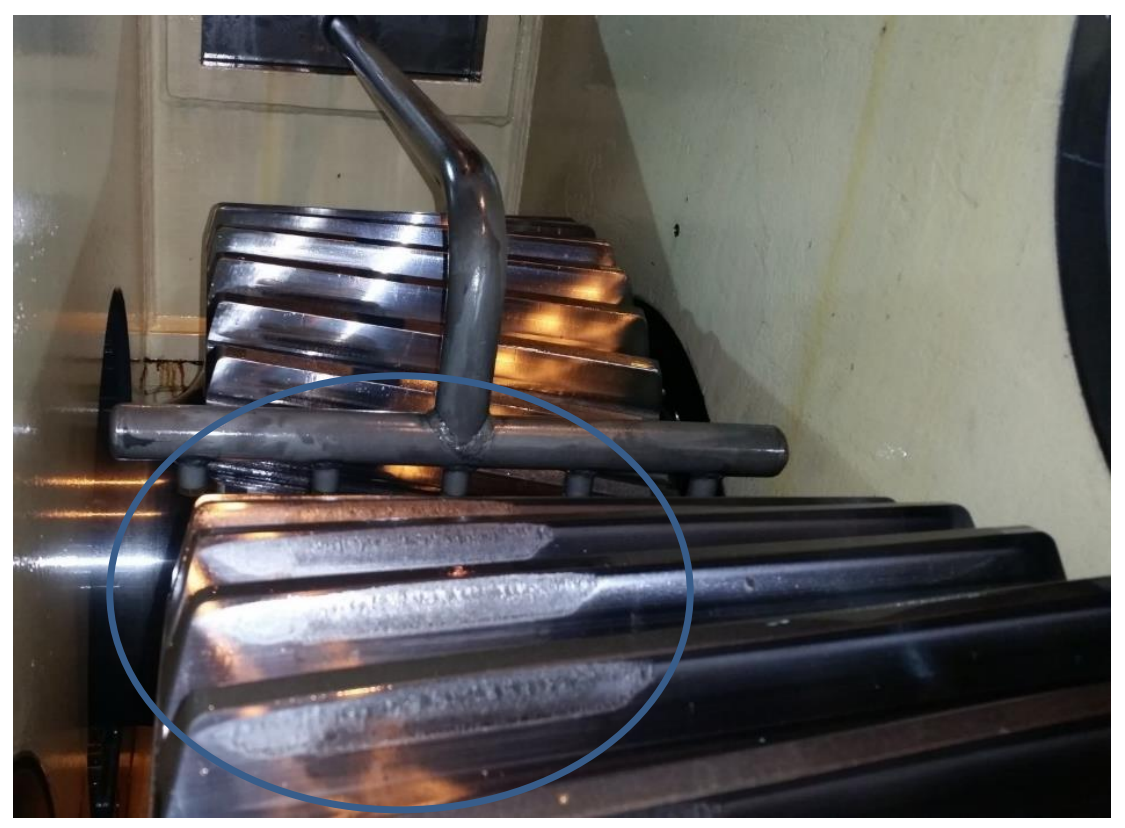

Figura 12 - Engrenagens da caixa redutora da cadeira 2 - Imagem 2

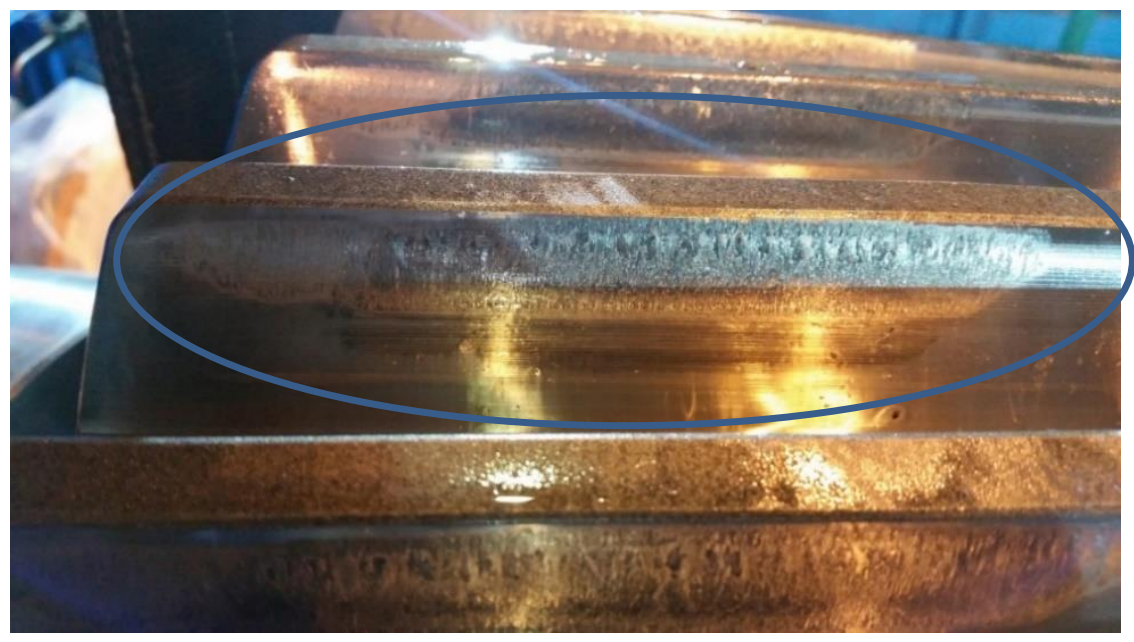

Figura 13 - Engrenagens da caixa redutora da cadeira 2 - Imagem 3

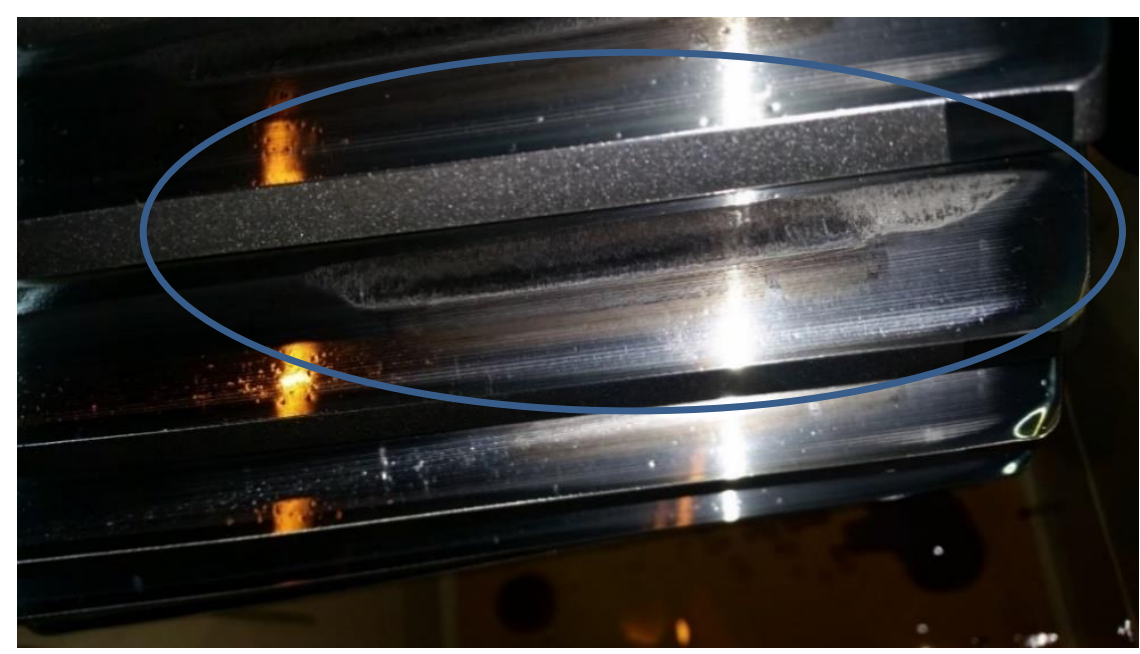


Com isso ficou comprovado que atuar nessa velocidade de laminação danos mais severos poderiam ocorrer nas engrenagens da caixa redutora.

\section{Caixa Redutora Cadeira 1}

Semelhante ao problema observado na cadeira 2. Foi detectado durante uma inspeção preventiva nas caixas redutoras um desgaste severo nos dentes das engrenagens da cadeira 1, conforme Figuras 15 a 18.

Figura 15 - Engrenagens da caixa redutora da cadeira 1 - Imagem 1.

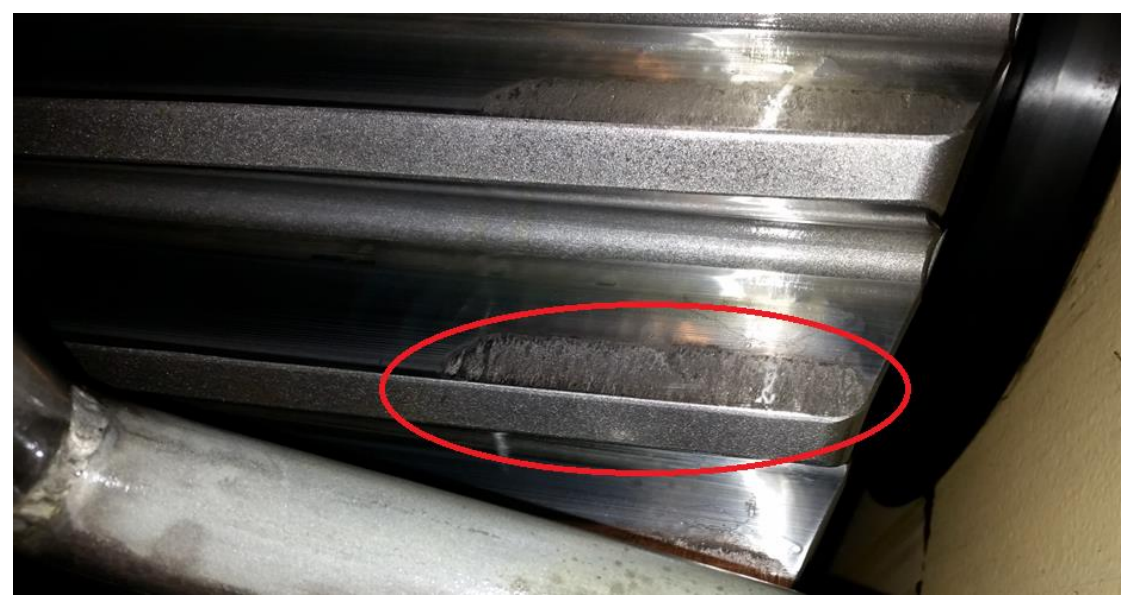

Figura 16 - Engrenagens da caixa redutora da cadeira 1 - Imagem 2.

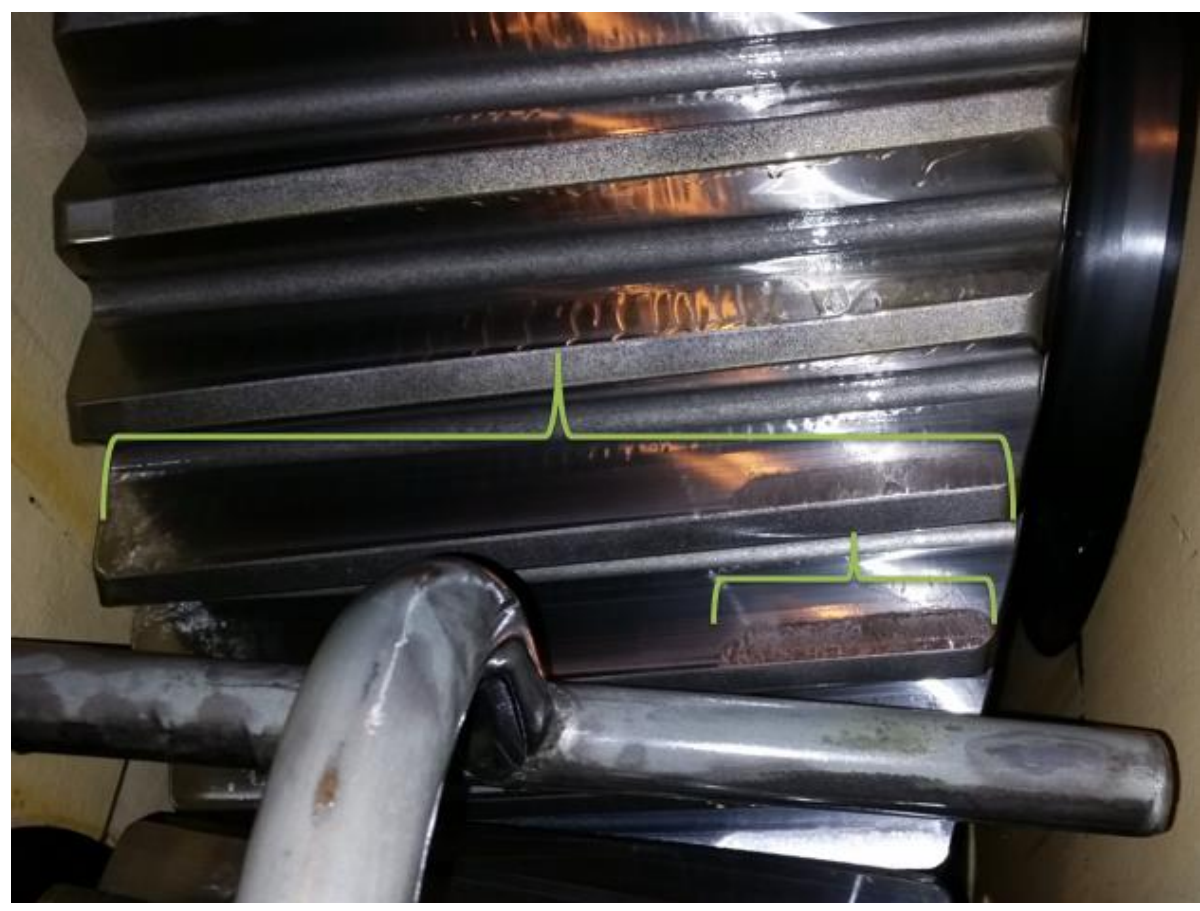


Figura 17 - Engrenagens da caixa redutora da cadeira 1 - Imagem 3.

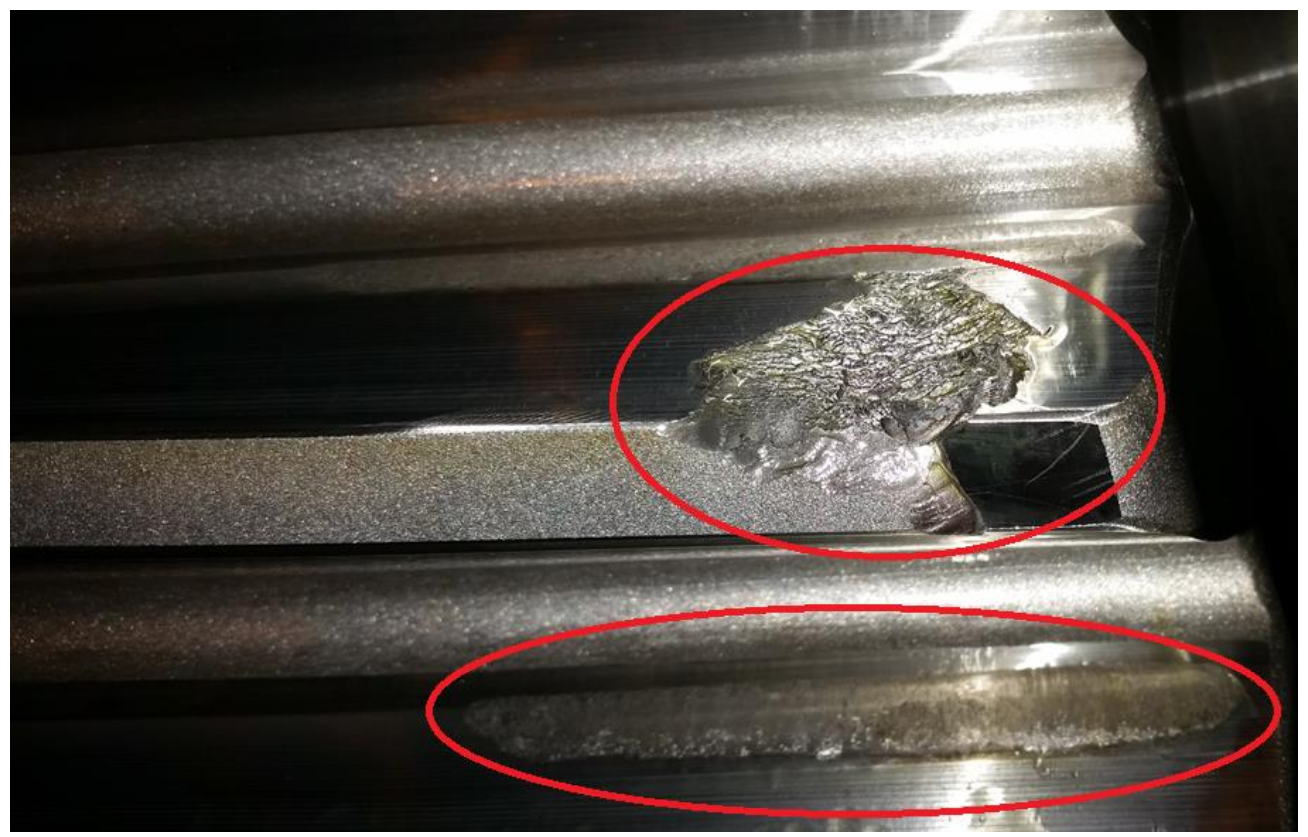

Figura 18 - Engrenagens da caixa redutora da cadeira 1 - Imagem 4.

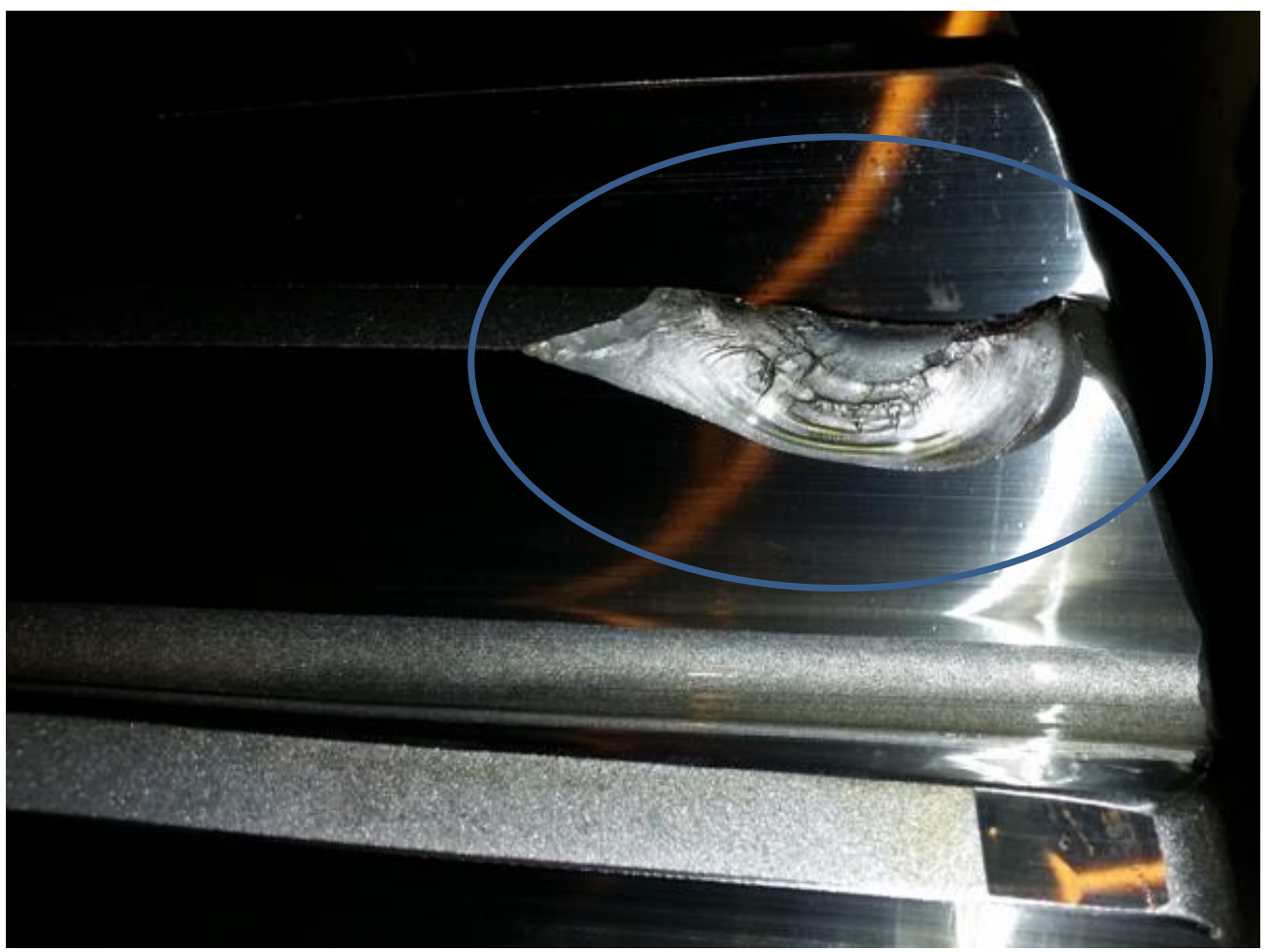

A velocidade média de operação da cadeira 1 é de 500 metros por minuto. As frequências fundamentais de engrenamento são igual a $270 \mathrm{~Hz}$. Fazendo o acompanhamento diário da evolução dos níveis de vibração nesta cadeira, observa-se que a situação vinha se agravando ao passar dos meses. Conforme Figuras 19 a 21. 
Figura 19 - Espectro de vibração 6 - 30 de agosto

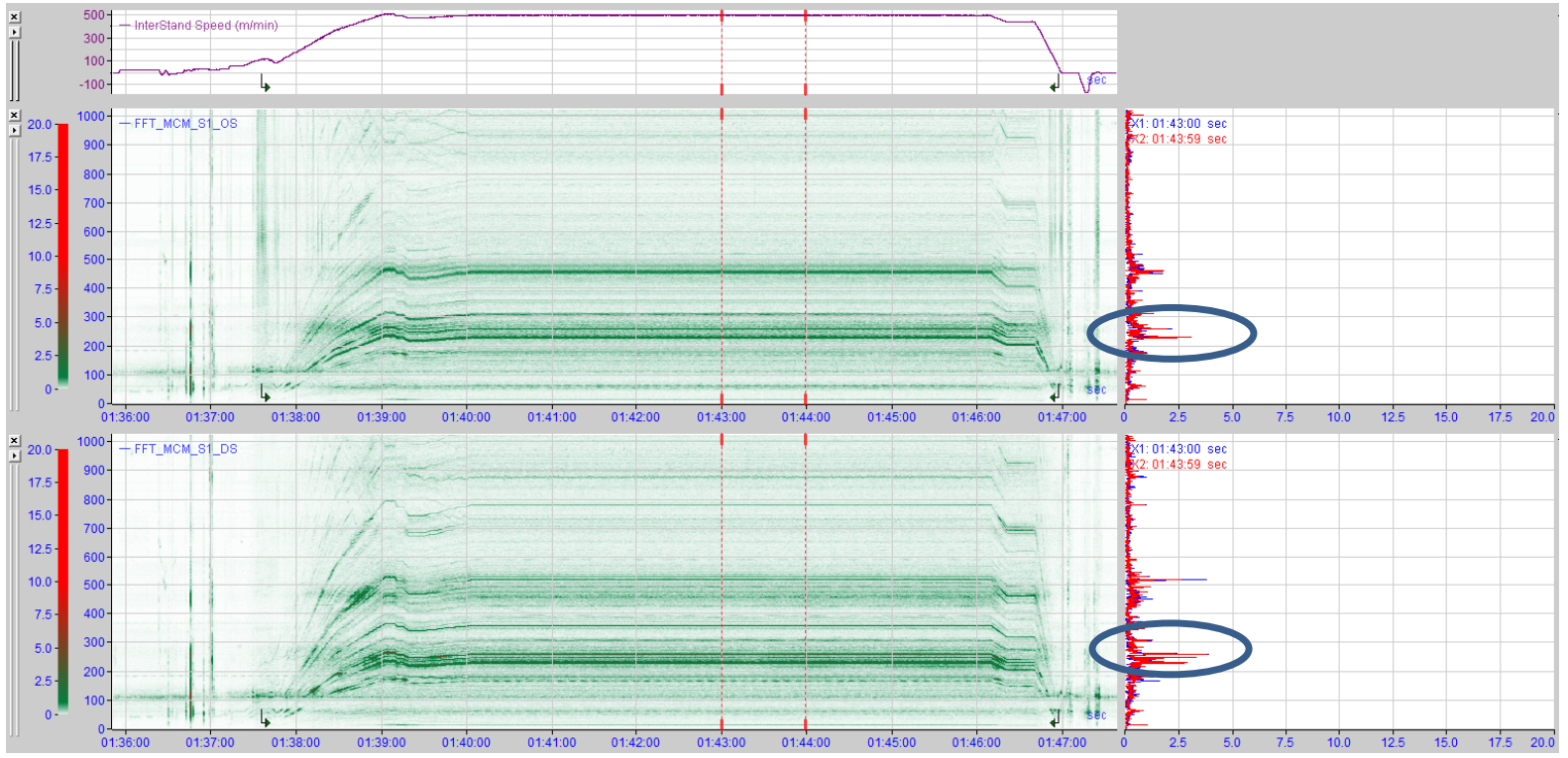

Figura 20 - Espectro de vibração 7 - 30 de outubro

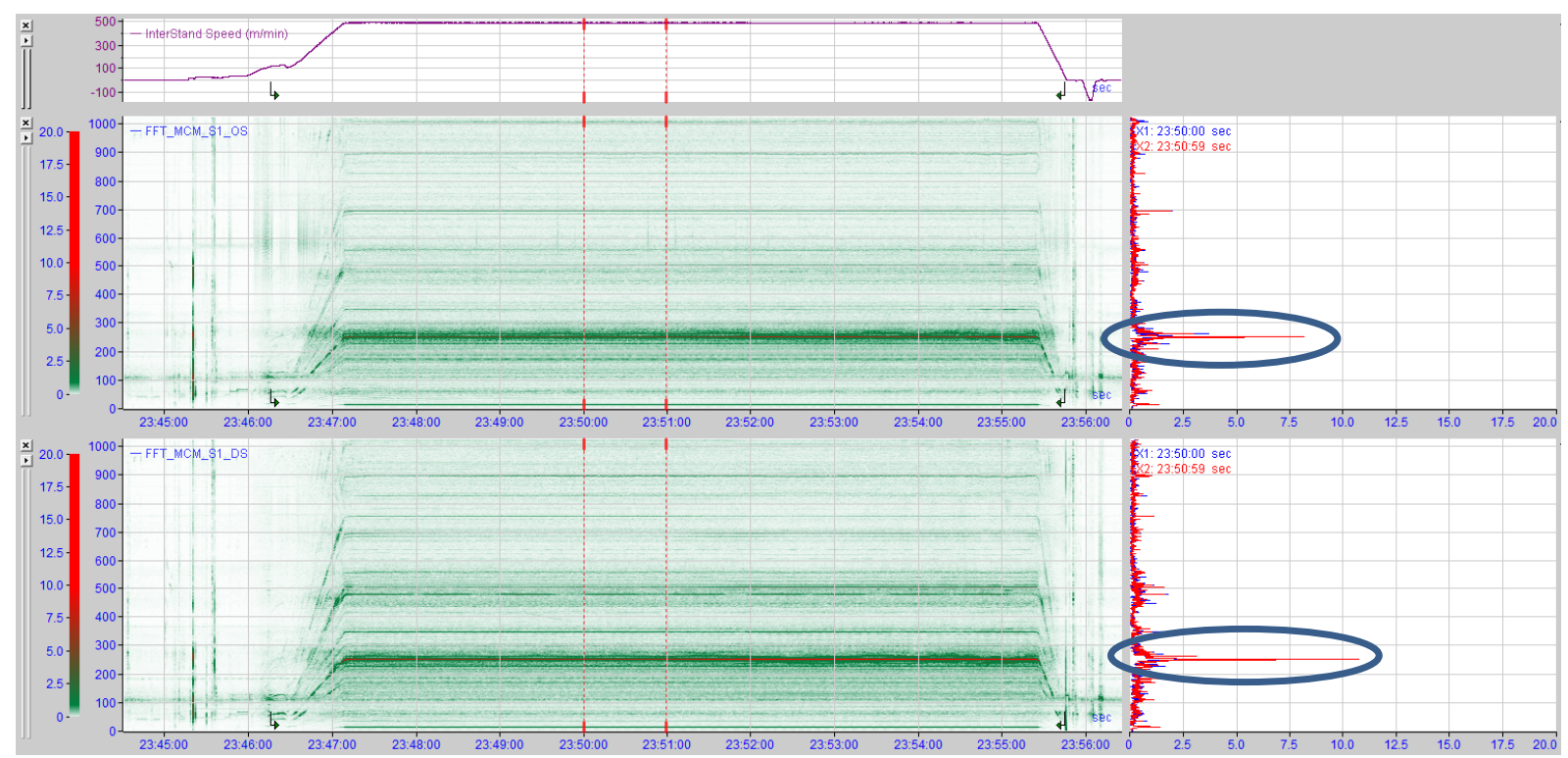

Figura 21 - Espectro de vibração 8 - 30 de novembro. 


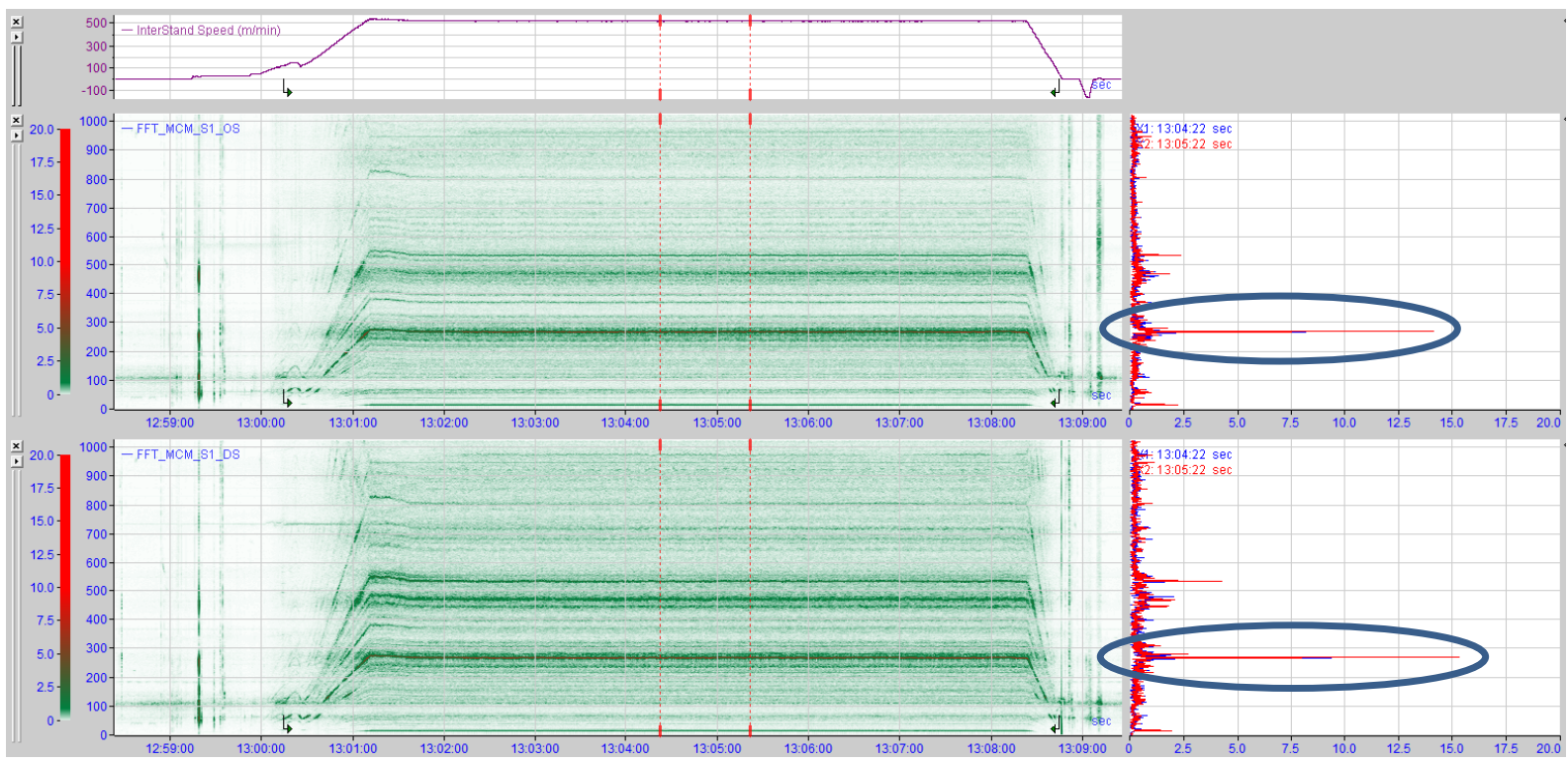

Como o monitoramento de vibração não estava sendo efetuado diariamente nessa cadeira, os danos causados nas engrenagens tiveram tempo para se propagar. Isto evidencia mais uma vez a importância do monitoramento de vibração nos equipamentos, pois se tivesse sido identificado em fase inicial, uma medida preventiva poderia ter sido adotada de forma mais apropriada.

\section{RESULTADOS E DISCUSSÃO}

\section{Regiao de Contato Cilindro de Trabalho e Spindle Pod}

Os níveis elevados de vibrações estavam ocorrendo a cada $16 \mathrm{~Hz}$, indicam que possivelmente seria encontrado algum problema nos cilindros de trabalho. Em etapa inicial foram analisados todos os cilindros de trabalho, medindo cuidadosamente todos os pescoços em busca de informações que comprovassem o desgaste da região de contato. Entretanto, esse desgaste não foi de fato encontrado. Partiu-se então para a inspeção do local onde o cilindro de trabalho fica apoiado dentro do laminador, e nesse caso sim, foi identificado que estava ocorrendo o desgaste do anel dentro do spindle pod.

Para atuar nesse problema foram confeccionados novos anéis, Figura 23, para que fossem trocados dentro do laminador. Os resultados obtidos após essa troca estão evidenciados no espectro de vibração registrados na Figura 24.

Figura 23 - Anel spindle pod 


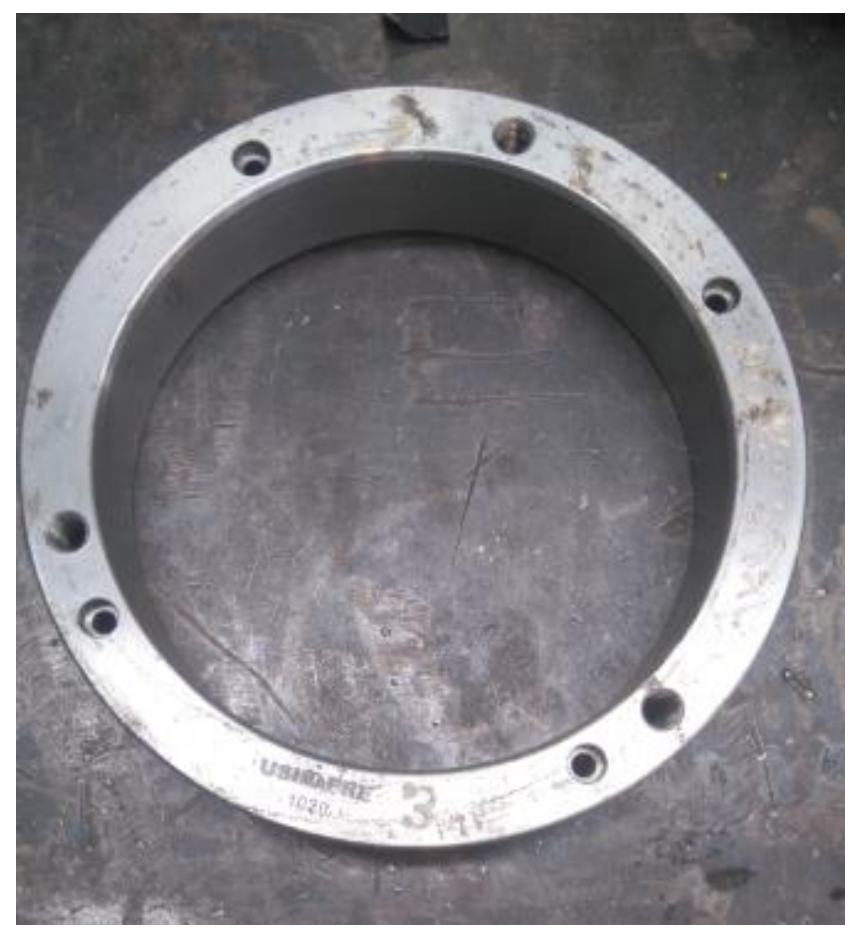

Figura 24 - Espectro de vibração 9

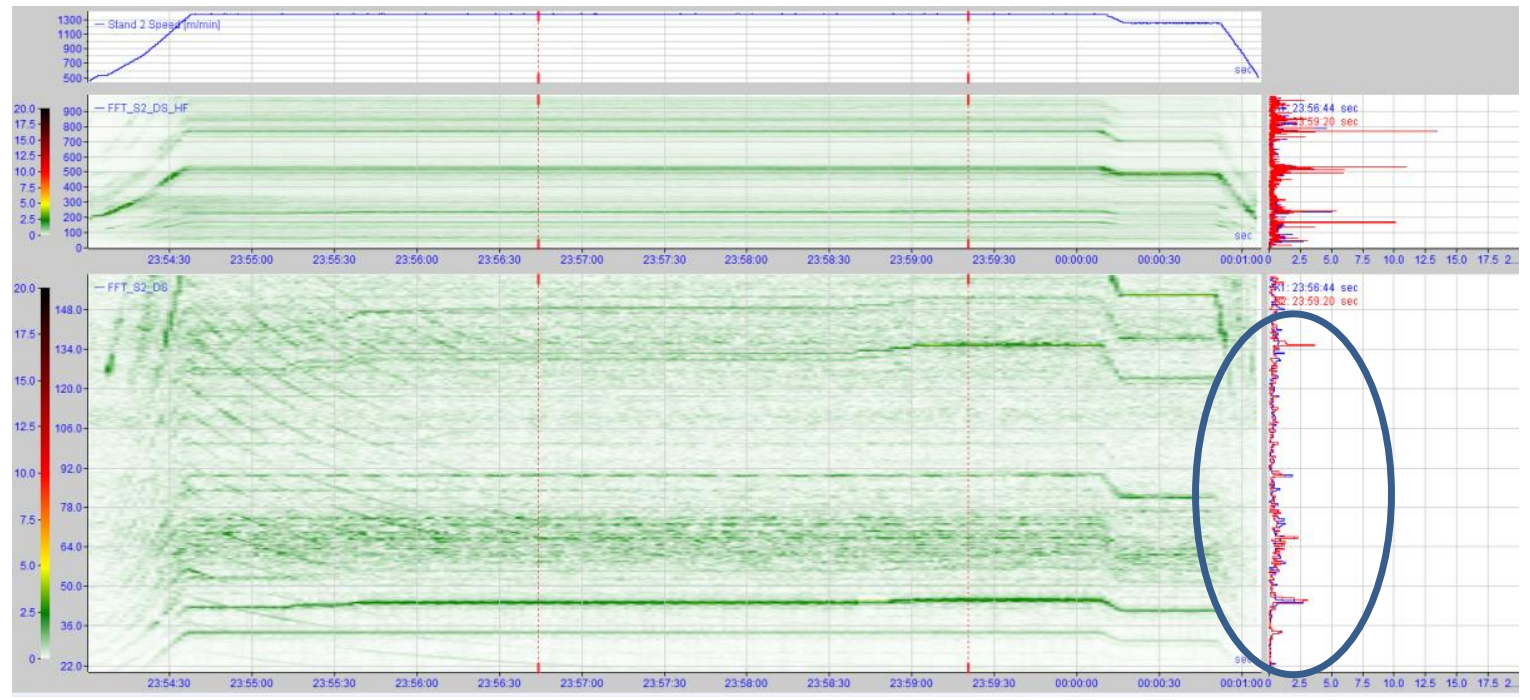

Comparando os dados obtidos entre o anel antigo e o anel novo pode-se concluir que houve uma melhora significativa nas vibrações registradas, Figura 25.

Figura 25 - Espectro de vibração - Anel antigo x Anel novo 

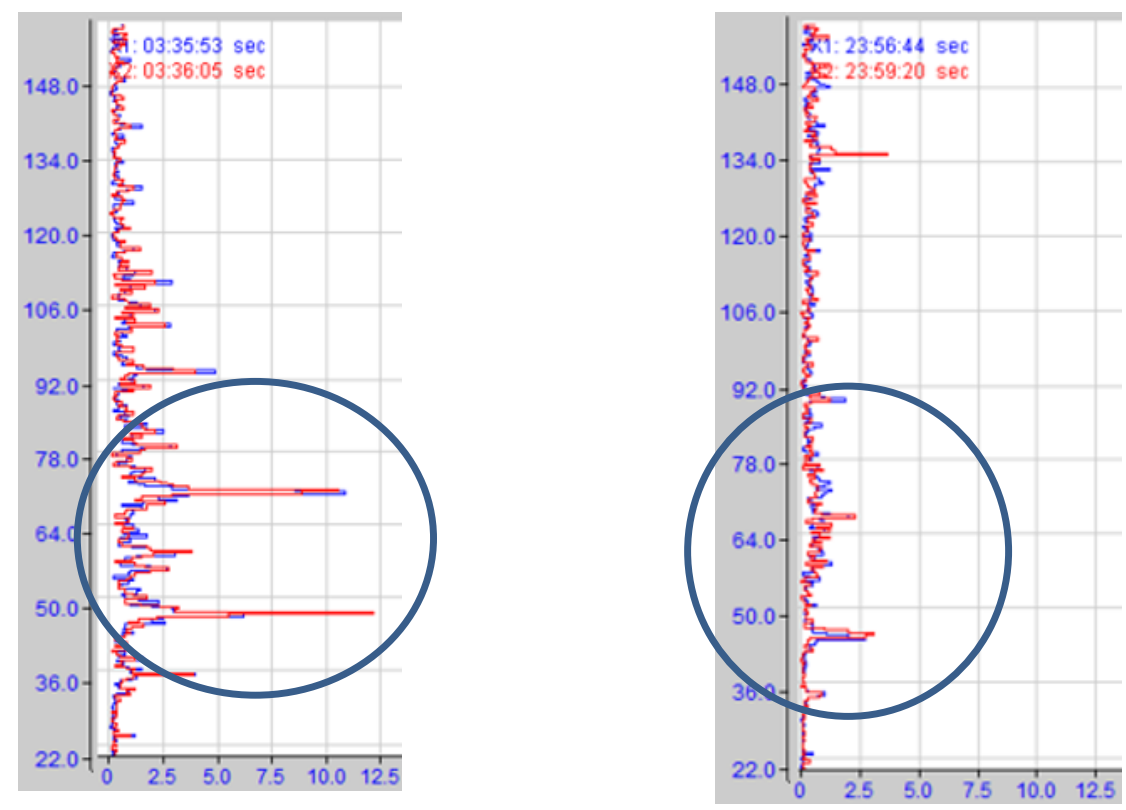

Mesmo com a troca do anel, verificou-se que após 5 meses, esses níveis de energia com amplitudes mais altas voltavam a ocorrer. Inspecionando novamente a região interna do spindles, obteve-se novamente a confirmação de desgaste na região M1, vertical. Por esse motivo torna-se fundamental que haja planos de manutenção preventiva para a inspeção dos anéis internos e a substituição dos mesmos sempre que necessário.

\section{Engrenamento Caixa Redutora da Cadeira 2}

Conforme indicado no espectro de vibração, as vibrações mecânicas na frequência de $700 \mathrm{~Hz}$ estavam sendo causadas devido a frequência fundamental de engrenamento estar em fase com uma das frequências naturais do laminador.

Uma solução para evitar que o sistema entre em ressonância é a limitação da velocidade de laminação, proibindo que o laminador opere acima da velocidade de 1000 $\mathrm{m} / \mathrm{min}$, nessa velocidade a frequência de engrenamento é $566 \mathrm{~Hz}$, longe da frequência natural do laminador. Mas, essa solução é economicamente inviável, uma vez que a velocidade de laminação está diretamente ligada a produtividade da fábrica.

Torna-se então viável uma adaptação ao conjunto de engrenagens de modo a "mover" a frequência fundamental de engrenamento. Entrando em contato com a fabricante do sistema de redução foi elaborado um novo projeto onde se alterou o número de dentes da caixa redutora do lado do motor. Foi reduzindo z1 de 39 dentes para 30 e z2 
de 46 para 35, mantendo o fator de redução da caixa próximo ao valor de projeto inicial, mas movendo a faixa da frequência de engrenamento para $600 \mathrm{~Hz}$.

Após a troca, ficou evidenciado a melhoria no conjunto, Figura 26 e 27. Pois o novo par instalado não apresentou problemas de instalação e nem entrou em fase com a frequência natural do laminador. 
Figura 26 - Espectro de vibração 10

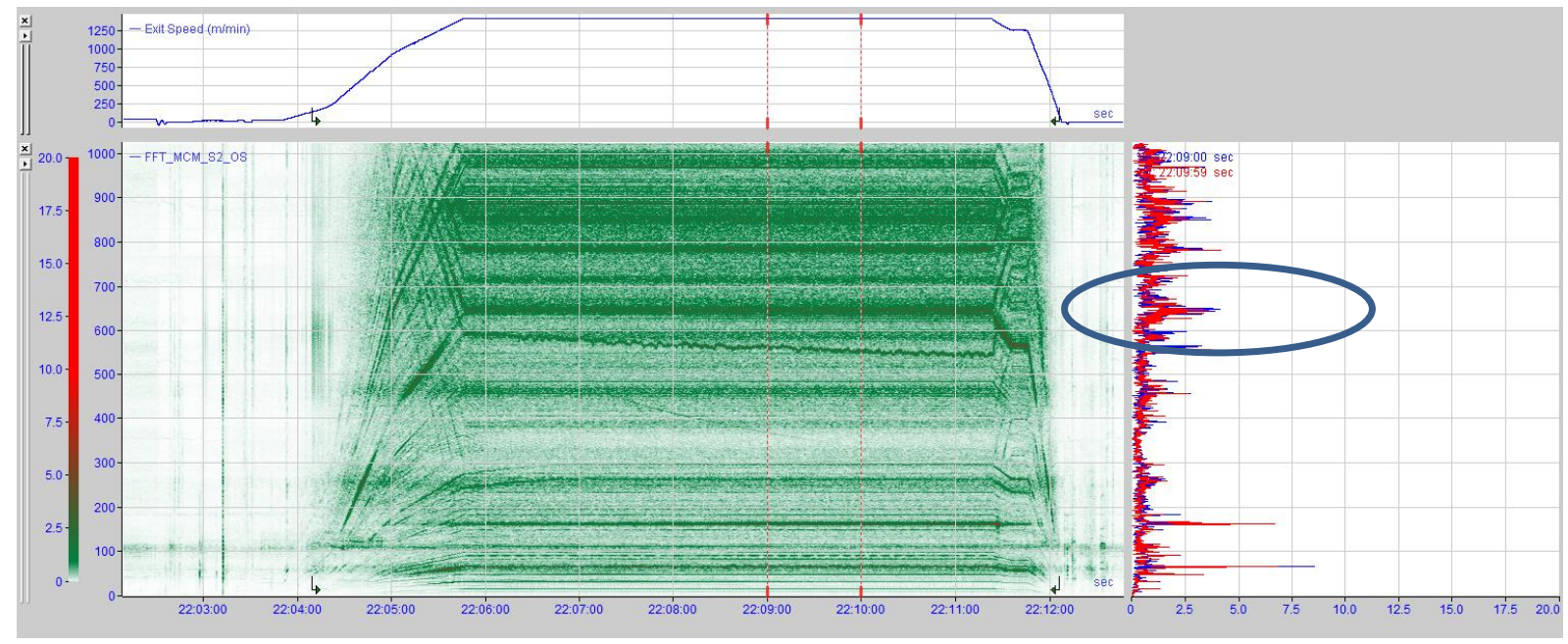

Figura 27 - Espectro de vibração 11

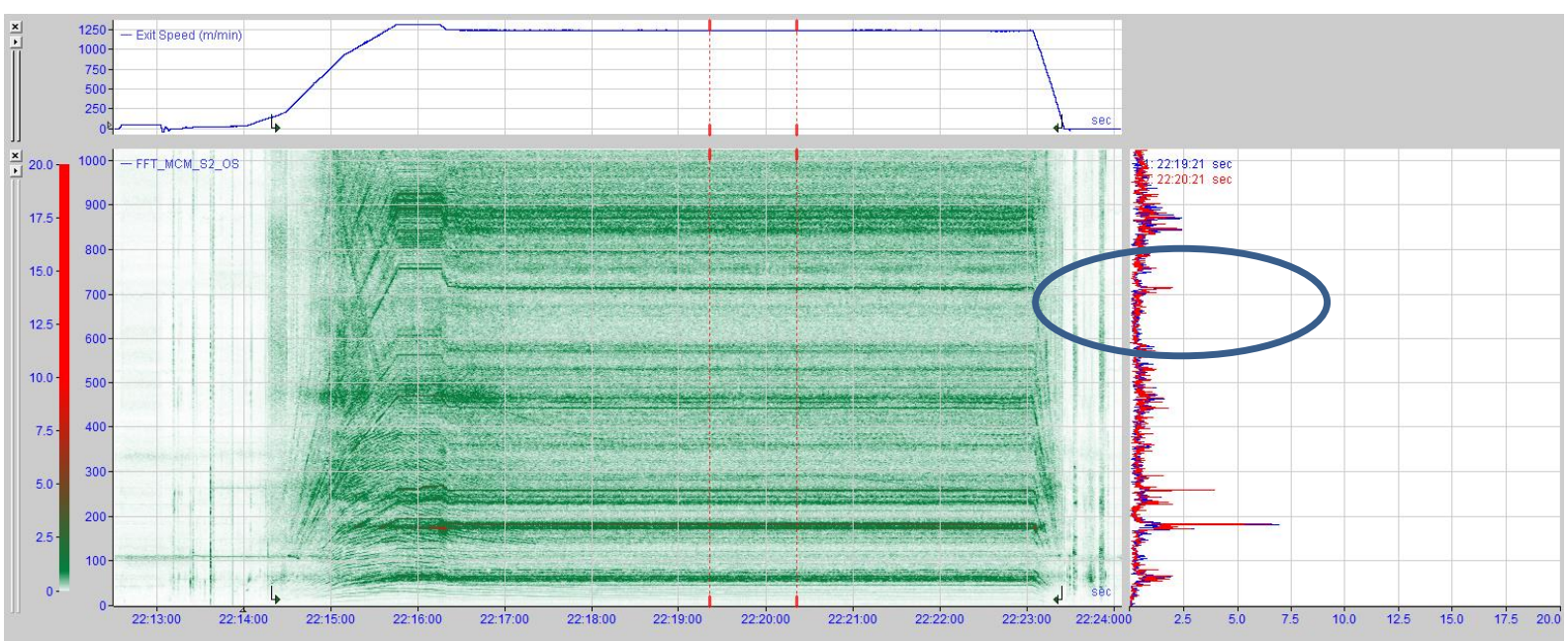

\section{Engrenamento Caixa Redutora da Cadeira 1}

O desgaste causado na engrenagem da cadeira 1 demorou para ser identificado, entretanto, uma boa análise de vibração no laminador, poderia ter evidenciado essa tendência e chamado a atenção para um problema em potencial do laminador.

Como medida de contingência, a caixa redutora foi aberta e os dentes danificados foram reparados, essa ação representou uma boa redução na amplitude de vibração registrados no laminador, Figura 28.

Figura 28 - Espectro de vibração 12 


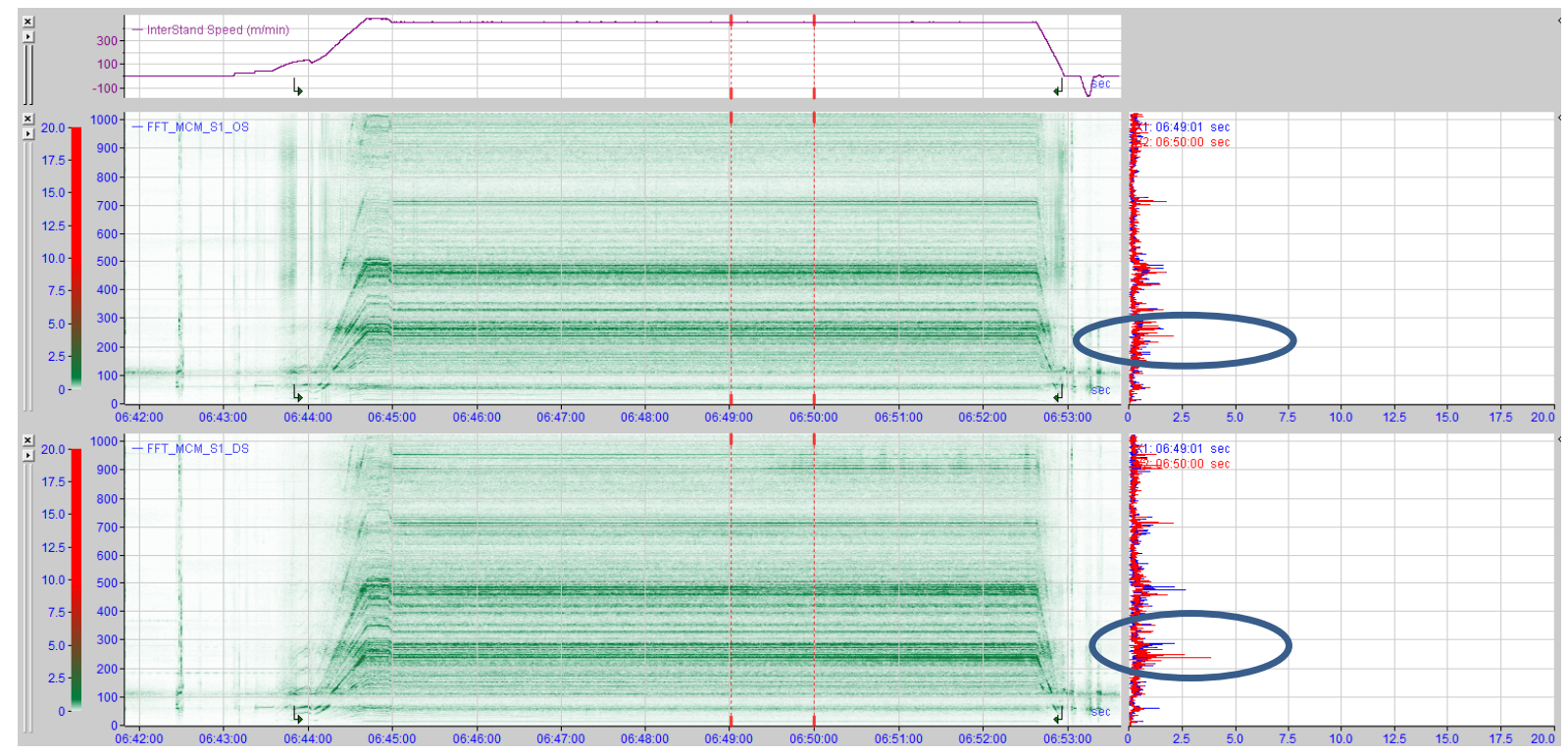

Cabe agora a equipe conduzir o mesmo estudo que foi efetuado para a cadeira 2, levantando as frequências naturais de vibração do conjunto redutor e verificar se a mesma não está em ressonância com a frequência fundamental de engrenamento. Caso essa seja a situação, deverá ser novamente estudado o projeto e modificá-lo de forma a distanciar essas frequências.

\section{CONCLUSÃO}

Dentre as fontes causadoras de vibração no laminador, a descoberta realizada com relação o anel do spindle pod teve grande valor para o atendimento dos objetivos deste trabalho. Ficou evidenciado que o desgaste deste anel gerava uma pequena folga entre o pescoço do cilindro de trabalho e o spindle pod, criando assim, a cada revolução destes cilindros, uma componente dinâmica de força que agia na vertical, essa força era então transmitida por todo o laminador, podendo causar danos nos cilindros, na chapa laminada ou em outras partes do equipamento.

Também ficou evidenciado a importância do monitoramento das frequências naturais do laminador e das frequências fundamentais dos eixos e engrenagens. Pois quando as duas entram no estado de ressonância, os níveis de vibração atingem amplitudes elevadas, podendo colapsar o equipamento. $\mathrm{O}$ desgaste das engrenagens ficou evidenciado através dos estudos realizados nas caixas redutoras das cadeiras 1 e 2 . 
Deve-se ter em mente que vibrações fazem parte de qualquer estrutura mecânica, e que equipamentos de ponta, onde altas velocidades são impostas no processo (aproximadamente $1800 \mathrm{~m} / \mathrm{mim}$ ), um estudo minucioso desse assunto deve ser executado. As vibrações irão sempre existir, por esta razão, deve-se monitorar sua amplitude, para que se possa agir de forma preventiva, evitando problemas na qualidade do produto final e também contribuindo na confiabilidade do equipamento.

Finalmente, vale mais uma vez reforçar a importância do monitoramento das vibrações em equipamentos mecânicos. Pois além de garantir que o mesmo opere de forma correta, garantindo a qualidade final do produto, os dados coletados podem auxiliar na identificação de problemas que acabam passando despercebidos em manutenções preventivas, dando um alerta para que a equipe se planeje com antecedência aos grandes problemas que podem ocorrem no equipamento.

\section{REFERÊNCIAS}

ARAUJO, L. A. D. Manual de Siderurgia: Transformação. $2^{a}$ Edição. ed. São Paulo: Arte \& Ciência, v. II, 1997.

BRESCIANI FILHO, E. et al. Conformação plástica dos metais. 6a. ed. Campinas: Editora da Unicamp, 2011. 254p.

CHIAVERINI, V., Tecnologia Mecânica. 2a ed. São Paulo: Mc Graw Hill, Volume II, 1986.

CIMM, Centro de informação metal mecânica. Disponível em <http://www.cimm.com.br/portal/material_didatico>. Acesso em: ago. 2015.

DIETER, G.E., Metalurgia Mecânica. 2. ed. Rio de Janeiro: Guanabara Koogan, 1981. $347 p$.

HU, P. H.; EHMANN, K. F. Fifth octave mode chatter in rolling. Northwestern University, Evanston, Illinois, 2001.

HU, P. H.; ZHAO, H.; EHMANN, K. F. Third-octave-mode chatter in rolling, Part I: chatter model. Department of Mechanical Engineering, Northwestern University, Evanston, Illinois, USA 2006, pp 1267-1277.

MABIE, H. H., FRED, W. O. Mecanismos e Dinâmica das Maquinas. 2. ed. Rio de Janeiro: Livros Técnicos e Científicos, 1980. 562p.

MACHADO, O. I., Jr. Estudo e aplicação de diferentes métodos de resolução para problemas dinâmicos não-lineares em presença de atrito. 2015. 57 f. Trabalho de Graduação (Graduação em Engenharia Mecânica) - Faculdade de Engenharia do Campus de Guaratinguetá, Universidade Estadual Paulista, Guaratinguetá, 2014. 
MEEHAN, P. A. W.; JOHN, E.; GLEN A. W. Modelling And Simulation of Vibration Phenomena in Rolling Mills. 7th International Conference on Steel Rolling, Tokyo, Japan - October 1998.

NOVELIS ROLLING GROUP. Novelis rolling course notes 2008. 2008.

REMN-MIN, G. Analysis of Dynamic Behaviors of Tandem Cold Mills Using Generalized Dynamic and Control Equations. IAS/IEEE Conference, Phoenix, AZ, Oct 9-13, 1999.

ROBERTS, W. L. Cold Rolling of Steel. New York: Marcel Dekker, 1978.

SKF. Estudo do comportamento dinâmico da cadeira do laminador CM3. 2013.

SLACK, N., BRANDON, A., JOHNSTON, R. Operations Management. 7a ed. Harlow: Pearson, 2013. 733p.

TAMIYA, T. F. K.; IIDA, H. Analysis of chattering phenomena in cold rolling. Proc. Int. Conf. on Steel Rolling, Tokyo (1980), pp.1191-1202.

YARITA, I.; FURUKAWA, K.; SEINO, Y. An Analysis of Chattering in Cold Rolling for Ultra Thin Gage Strip Steel. Transactions of the Iron and Steel Institute of Japan, Vol. 19, 1978, p 1-10.

YUN, I. S. Chatter in rolling. PhD Thesis, Northwestern University, Evanston, Illinois, 1995. 